\title{
SciDoC
}

Infer, Interpret \& Inspire Science

International Journal of Dentistry and Oral Science (IJDOS)

ISSN: $2377-8075$

\section{Main Predictors of Root Canal Endodontical Treatment: Systematic Review}

Review Article

Maciel Filho $\mathrm{MD}^{1}$, Zotarelli-Filho $\mathrm{IJ}^{2 *}$, Linhares de Castro FP ${ }^{1,2}$

${ }^{1}$ University Center North Paulista (Unorp) - São José do Rio Preto, SP, Brazil.

${ }^{2}$ Post Graduate and Continuing Education (Unipos), Street Ipiranga, São José do Rio Preto SP, Brazil.

\section{Abstract}

Introduction: Defective apical seals were identified as the main cause of failures in endodontic treatment, and several studies have emphasized the importance of adequate coronal sealing between sessions for successful endodontic therapy. Sodium hypochlorite is an irrigant solution widely used in chemotherapeutic treatment for a long time with great effectiveness. Gluconate chlorhexidine is a newer product but with excellent properties but there is still considerable controversy over which is the best product for the treatment of the canal.

Objective: The objective of the present study was to perform a systematic review on the importance of the clinical use and outcomes of Chlorhexidine gluconate, Sodium hypochlorite and Coltosol ${ }^{\mathbb{}}$ in endodontic treatment of canals.

Methods: The words were included Treatment dental root. Chlorhexidine gluconate, Sodium hypochlorite and Coltosol ${ }^{\mathbb{B}}$. For further specification, the root canal irrigation description for refinement was added during searches. The literature search was conducted through online databases: Pubmed, Periodicos.com and Google Scholar. It was stipulated deadline, and the related search covering all available literature on virtual libraries. A total of 55 articles were found involving temporomandibular dysfunction. Initially, it was held the exclusion existing title and duplications in accordance with the interest described this work. After this process, the summaries were evaluated and a new exclusion was held. A total of 41 articles were evaluated in full, and 30 were included and discussed in this study.

Conclusion: Chlorhexidine gluconate, sodium hypochlorite and Coltosol ${ }^{\mathbb{B}}$ have great fundamental properties for endodontic treatment and neither product can be disregarded. It is only necessary to analyze in detail when hypochlorite should be used and when chlorhexidine gluconate can be used that can be used alternately in the preparation of the endodontic canal and should not be used simultaneously, since the interaction between the two products provides a high toxicity. Already Coltosol ${ }^{\mathbb{R}}$ prey expansion can cause significant strains in the remaining coronary structure.

Keywords: Chlorhexidine Gluconate; Sodium Hypochlorite and Coltosol ${ }^{\circledR}$.

\section{Introduction}

The success of endodontic treatment is directly related to the observance of all principles recommended for the treatment of root canals such as complete cleaning, disinfection and elimination of all and any residual channel system and modeling prior to restoration $[1-3]$.

The preparation of the canal is highly influenced by the complexity and anatomical variability of the root canals that have recesses, side channels, accessories, secondary, isthmuses, oval channels, multiple foramina and apical deltas, making it difficult to clean and disinfect the endodontic system.

Residual remains, bacteria, remains of necrotic pulp tissue and dentin fragments are common, and may be a nutrient medium for resilient bacteria [4]. The biomechanical preparation of the root canals occurs by three means: mechanical, chemical and physical. In this way the cleaning and disinfection of the channels does not only depend on the instrumentation but also on the chemi-

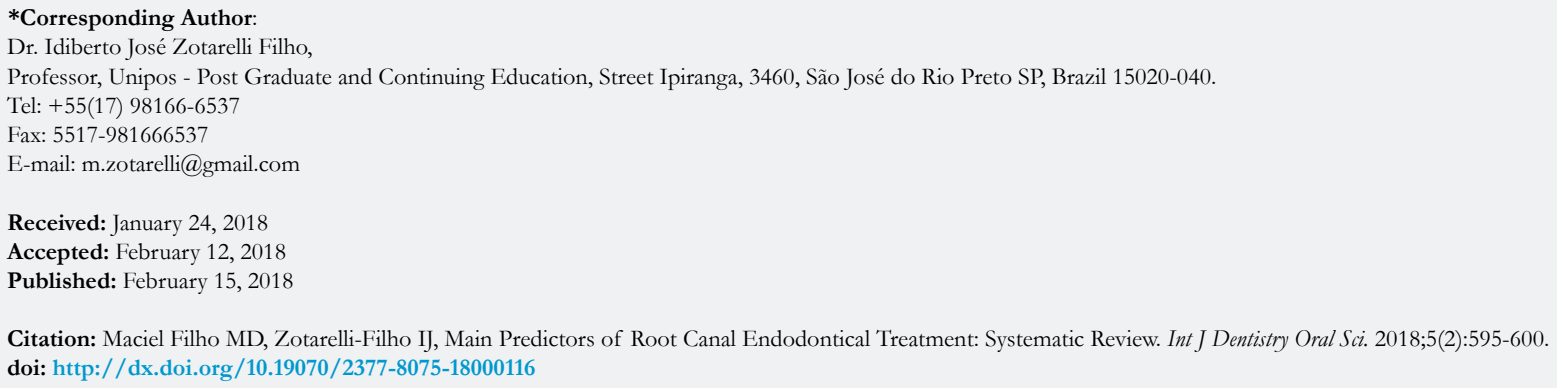

Copyright: Zotarelli-Filho IJ ${ }^{\circ}$ 2018. This is an open-access article distributed under the terms of the Creative Commons Attribution License, which permits unrestricted use, distribution and reproduction in any medium, provided the original author and source are credited. 
cal action of irrigating solutions with chemical properties such as solvency, antimicrobial activity and physical action of irrigation and aspiration $[3,4]$.

The instruments have a limited action, reaching only the main channel light, do not reach the complex channel system, and approximately $50.0 \%$ of the channel walls remain uninsulated during the mechanical preparation, resulting in insufficient cleaning $[4,5]$.

Due to the limited action of the instruments, it is necessary to associate chemical substances with the instrumentation process in order to facilitate the action of the instruments, reaching the entire channel system, sanitizing the endodontic complex [7].

Other authors recommend the addition of chemical substances to the mechanical preparation in order to intensify the disinfection, obtaining a greater emptying and widening of the canal through the combination of chemical substance and endodontic instrument $[8,9]$. The irrigating liquid through physical action promotes hydraulic circulation through the interior of the canal, eliminating organic matter as well as fragments of dentin. This results in the decomposition of organic and inorganic tissues and the sanification of the canal $[9,10]$.

Sodium hypochlorite $(\mathrm{NaOCl})$ has been widely used worldwide since 1792 in medicine. In endodontia sodium hypochlorite, then known as the Dakin solution, was introduced by Barret in 1917 as a root canal irrigation solution with proven efficacy and antiseptic efficacy [11]. Coolidge also used sodium hypochlorite as a method of cleaning and disinfecting root canals in order to improve the results [12]. Walker in 1936, began to use root canal treatment with necrotic pulps solution irrigator with $5.0 \%$ sodium hypochlorite [13].

However, Grossman in 1943 was the major disseminator of the sodium hypochlorite solution irrigator with the use of channel irrigation technique alternating sodium hypochlorite at $5.0 \%$ hydrogen peroxide $3.0 \%$, the reaction of the two substances culminated in effervescence with release of oxygen, favoring the extinction of microorganisms and channel residues [14]. Sodium hypochlorite belongs to the group of halogen compounds available in concentrations of 0.5 to $5.3 \%$ and up to $10.0 \%$ for clinical use [15].

Several studies aimed at evaluating the effects of sodium hypochlorite solutions on the decomposition of pulp tissue, on dentin permeability, on the cleaning of the canal and its bactericidal action, in its different concentrations emphasizing the superiority of sodium hypochlorite solutions compared to other auxiliary solutions of the channel preparation [16]. Since sodium hypochlorite has been used for a long time, its results are already widely proven, based and consolidated in the international literature.

On the other hand, chlorhexidine appeared through studies with the aim of finding a new antimalarial agent, being developed poly biguanide compounds that had a significant antimicrobial potential called cationic detergent and later gluconate chlorhexidine. This compound was the basis for the production of a salt that reached the consumer market under the name of chlorhexidine gluconate in 1954 [16].

As chlorhexidine gluconate exhibits an excellent degree of skin affinity, it is the first international antiseptic indicated for skin asepsis due to its good antibacterial activity and low levels of toxicity. Chlorhexidine gluconate was introduced in dentistry around 1959 for the control of bacterial plaques and its use, in general, occurred around $1970[16,17]$.

Among the main advantages of chlorhexidine gluconate are: enlargement and modeling of the canal system, elimination of microorganisms and their by-products, live or necrotic pulp tissue [16]. There are still many disagreements as to which chemical agent would have its most suitable qualities for the irrigation of the canal system provoking numerous discussions and controversies between the defenders of sodium hypochlorite and chlorhexidine gluconate, which justifies if we analyze in more detail the literature produced in the the last 10 years on the employment advantages and disadvantages of each product [17].

Further, the ideal temporary crown sealer should promote good marginal sealing, minimum porosity, dimensional stability, abrasion and compression resistance, be easy to insert and remove, biocompatible, esthetic, low cost, low solubility and antimicrobial activity $[20,21]$. Defective apical seals were identified as the main cause of failures in endodontic treatment, and several studies have emphasized the importance of adequate coronal sealing between sessions for successful endodontic therapy [20].

The persistence of microorganisms and reinfection of root canal, or both are the main factors that contribute to the failure of endodontic treatment $[20,21]$. For this reason, avoiding marginal infiltration, keeping the delay dressing intact becomes a prerequisite, and this is possible by placing a good temporary coronary sealing [22]. Solubility, thermal expansion, porosity and contraction are significant variables in the clinical performance of these materials $[22,23]$.

The use of temporary restorative materials in endodontics is of extreme importance because it prevents contamination of the root canal, preventing infections and allowing the action of the medication used as a dressing for delay when the treatment is done in sessions [24]. The temporary restorer Coltosol $^{\circledR}$ is composed of a mixture of: zinc oxide, monohydrate zinc sulfate, calcium sulfate hemihydrate, diatomaceous earth, ethylene-vinyl acetate copolymer and mint flavor.The hygroscopic expansion of Coltosol ${ }^{\circledR}$ corresponds to $17.0-20.0 \%$ of its volume, and its prey is directly linked to fluid absorption, thus hygroscopic expansion together with masticatory forces are directly related to crown fracture endodontically treated teeth [25].

The temporary restorative Coltosol ${ }^{\circledR}$ (Coltène) is composed of a mixture of: zinc oxide, monohydrate zinc sulfate, calcium sulfate hemihydrate, diatomaceous earth, ethylene-vinyl acetate copolymer and peppermint flavor [25]. The hygroscopic expansion of Coltosol ${ }^{\circledR}$ corresponds to $17.0-20.0 \%$ of its volume, and its prey is directly linked to fluid absorption, thus hygroscopic expansion together with masticatory forces are directly related to dental fracture of crowns of endodontically treated teeth [25].

Thus, the sealing material, however, can in turn provide antimicrobial activity, allowing the reduction or elimination of microorganisms that remain in the cavity or that penetrates through micro filtrations in the coronary sealant $[20,26]$. 
The objective of the present study was to perform a systematic review on the importance of the clinical use and outcomes of Chlorhexidine gluconate, Sodium hypochlorite and Coltosol ${ }^{\circledR}$ in root canal endodontical treatment.

\section{Methods}

Experimental and clinical studies were included (case reports, retrospective, prospective and randomized trials) with qualitative and/or quantitative analysis. Initially, the key words were determined by searching the DeCS tool (Descriptors in Health Sciences, BIREME base) and later verified and validated by MeSh system (Medical Subject Headings, the US National Library of Medicine) in order to achieve consistent search.

\section{Mesh Terms}

The words were included treatment root canals. Chlorhexidine gluconate, Sodium hypochlorite and Coltosol ${ }^{\circledR}$. For further specification, the root canal irrigation description for refinement was added during searches. The literature search was conducted through online databases: Pubmed, Periodicos.com and Google Scholar. It was stipulated deadline, and the related search covering all available literature on virtual libraries.

\section{Series of Articles and Eligibility}

A total of 55 articles were found involving temporomandibular dysfunction. Initially, it was held the exclusion existing title and duplications in accordance with the interest described this work. After this process, the summaries were evaluated and a new exclusion was held. A total of 41 articles were evaluated in full, and 30 were included and discussed in this study.

\section{Literature Review}

Sodium hypochlorite belongs to the group of halogen compounds, it is an active chlorine solution with a high $\mathrm{pH}$ around 11 to 12 , it is more stable promoting the release of chlorine in a slower way due to the action of hydroxyl ions [2]. In order for a sodium hypochlorite solution to be effective its properties must be preserved by suitable chemical standards as the shelf life and as close as possible to the date of manufacture, storage in amber glass away from the light and preferably in the refrigerator, and the same concentration as described on the label by the manufacturer, excess light and heat lead to loss of the chlorine content of hypochlorite $[3,4]$.

It is essential that the dental surgeon obtain a good quality hypochlorite with adequate concentration, it is common to find some products outside the specifications described on the packaging label. Factors such as instability and climate in our country (high temperatures, sunlight) facilitate the loss of active chlorine concentration more rapidly over time making the solution ineffective $[5,6]$. Chlorhexidine gluconate is available on the market under liquid or gel at different concentrations, the most used in dentistry is $2.0 \%[6,7]$. Chlorhexidine gluconate is used as a channel irrigant solution and intracanal medication (alone or in combination with other substances). Chlorhexidine has a mild acid character, with a more stable $\mathrm{pH}$ ranging from 5 to 8.0, but its higher antibacterial efficiency is concentrated in the $\mathrm{pH}$ range of 5.5 to 7 [8].

\section{Antimicrobial Activities}

Sodium hypochlorite presents different concentrations and has great advantages as: tissue solvent, its high alkaline $\mathrm{pH}$ neutral-

\section{Flow Chart}

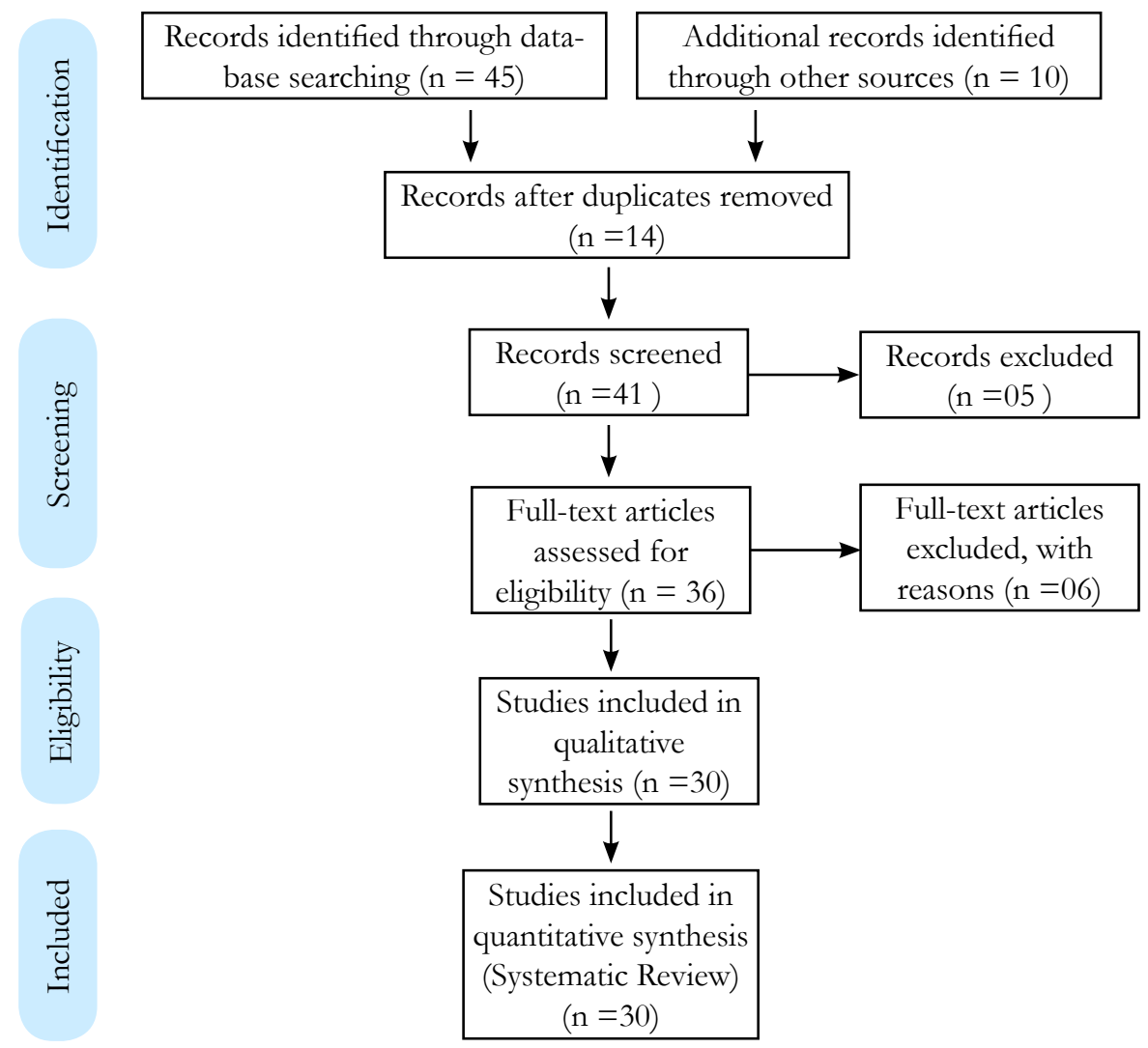


izes the acidity of the medium, making it unsuitable for bacterial development, forming as a powerful bactericide and also the formation of hypochlorous acid and release of chlorine leads to the saponification of fats, destruction of the membrane phospholipid layer of bacteria [9-11].

The high $\mathrm{pH}$ of sodium hypochlorite interferes in the integrity of the cytoplasmic membrane, inhibiting the enzymes irreversibly, causing biosynthetic changes in the cellular metabolism leading to irreversible inactivation of bacterial enzymes, forming as an excellent effective antimicrobial agent and organic solvent [12].

The concentration of sodium hypochlorite is proportional to its antimicrobial and solvent activity, that is, the more concentrated the sodium hypochlorite solution, the greater its antimicrobial activity [13]. Sodium hypochlorite solutions with chlorine concentrations below $0.3 \%$ have no effect on microorganisms such as Candida albicans and Streptococcus faecalis $[2,3]$.

In their study Chandra et al., [7] found that 5.3\% sodium hypochlorite had superior antimicrobial efficacy compared to chlorhexidine gluconate $2.0 \%$ and EDTA $17.0 \%$ when used alone. Already in association with $1 \%$ clotrimazole, $5.3 \%$ sodium hypochlorite and $2.0 \%$ chlorhexidine gluconate also showed significantly higher antifungal properties than EDTA at $17.0 \%$, proving that clotrimazole associated with gluconate of chlorhexidene $2.0 \%$ or sodium hypochlorite $5.3 \%$ were effective in combating $C$. albicans in the final irrigation of the root canals.

The study by Ferraz et al., [9] compared the action of the antimicrobial activity of chlorhexidine gluconate $0.2 \%$ gel; $1.0 \%$ and $2.0 \%$, liquid chlorhexidine gluconate and sodium hypochlorite at various concentrations as an irrigating solution. It was found that the chlorhexidine gluconate at $2.0 \%$ gel presented a statistically significant difference when compared to sodium hypochlorite and liquid chlorhexidine gluconate, proving its great antimicrobial potential.

Some studies recommend the use of $2.5 \%$ sodium hypochlorite as the first choice to obtain quality sanitation, but emphasize the importance of controlling the volume of solution used and the contact time in the channel system during the mechanical chemical preparation [13-16].

Ribeiro et al., [15] warns that the higher the concentration of sodium hypochlorite solutions, the greater the loss of collagen; in the case of solutions at $5.3 \%$ there are negative effects on tooth properties, reducing their flexural strength and dentin elasticity. On the other hand Pretel et al., [14] recommends sodium hypochlorite in the concentration of $2.5 \%$ to $5.3 \%$, as the most indicated in the necroses because it presents a better antimicrobial effect against resistant microorganisms like Enterococos faecalis and Candida albicans, but smaller concentrations as $0.5 \%$ and $1 \%$ can be used in biopulpectomies.

One of the main disadvantages of sodium hypochlorite is the high irritability of the periapical tissues, high concentrations [17]. When analyzing the antimicrobial action of $2 \%$ chlorhexidine gluconate, $1 \%$ sodium hypochlorite and paramure chlorophenol combined with furacin against strains of $S$. aureus, C. albicans, E. faecalis and P. aureginosa, Semenoff et al. (2010) and found that both $2.0 \%$ chlorhexidine gluconate and $1.0 \%$ hypochlorite had higher inhibition factors in that the PMC paramnonchlorophene combined with furacin was not effective against the tested microorganisms. In this way, the supremacy of both chlorhexidine gluconate and hypochlorite was proved to be bacteriostatic.

Chlorhexidine gluconate acts by adsorption on the cell wall of the microorganism attacking the cytoplasmic membrane of the bacterium, causes precipitation and coagulation of the cytoplasm, leading to osmotic imbalance, resulting in extravasation of the intracellular material $[17,18]$. Chlorhexidine gluconate can be both bacteriostatic at low concentration $(0.2 \%)$ causing inhibition of ATP synthesis of bacteria and bactericide at high concentrations $(2 \%)$ causing cytoplasmic membrane rupture, that is, it depends on the concentration used [14].

The action of chlorhexidine gluconate is broad spectrum acting against a large number of aerobic and anaerobic bacteria and against Gram-positive and Gram-negative species, with Grampositive being highly susceptible to Gram-negative species [17]. Chlorhexidine gluconate has a long-lasting antibacterial and disinfectant effect that can be extended from day to week, with the ability to control the growth of Gram-positive and Gram-negative bacteria $[18,19]$.

Although chlorhexidine gluconate does not exhibit the ability to dissolve organic tissues, it has other advantages that compensates for this deficiency, such as chlorhexidine gluconate gel that favors instrumentation, elimination of organic tissues, keeps the "active principle" in contact with the microorganisms for long periods and growth inhibitory effect [13].

Both liquid chlorhexidine gluconate and $2.0 \%$ gel are widely effective against various bacterial species but the $2.0 \%$ gel exhibits a high inhibitory growth power including Enterococcus faecalis and Staphylococcus aureus and yeast and fungi, in particular Candida albicans. Chlorhexidine gluconate does not have an effective efficacy in organic matter, mycobacteria, bacterial spores and viruses [13]. For Bonan, Batista, Hussne [6] sodium hypochlorite and chlorhexidine gluconate both exhibit antimicrobial action, a primordial and indispensable quality in an endodontic solution.

The antimicrobial activity is aggregated to the sealing action of these products, contributing in the performance to decrease or eliminate foci of growth of components of the oral microbiota present in the coronary portion during or after the endodontic therapy $[2,3]$. However, the antimicrobial activity of the temporary coronary sealers employed in the intracanal medication phase or the waiting period of the definitive restoration is a subject that has not been much approached $[3,4]$.

\section{Importance use of Coltosol $^{\circledR}$}

The literature has shown that the Coltosol ${ }^{\circledR}$ sealer showed the best results, corroborating with different authors [20-24]. Coltosol $^{\mathbb{R}}$, as well as Citodur ${ }^{\mathbb{R}}$ and Cavit $^{\circledR}$ are ready-to-use materials, without the need for any mixing and easy manipulation. Coltosol ${ }^{\mathbb{R}}$ determined the highest mean of microbial growth inhibition halos and was indicated in the study samples as the best antimicrobial property in vitro. Another study stated that the Cavit ${ }^{\circledR}$ sealer has a very similar composition to Coltosol $^{\circledR}$, having a zinc-related antibacterial activity $\left(\mathrm{Zn}^{2+}\right)$, due to the dissociation of zinc oxide 
and zinc sulfate present in the formulation [26].

Further, Coltosol ${ }^{\circledR}$ and materials based on barium sulfate have a high hygroscopic characteristic, which gives them linear expansion when in contact with water, generating literary conflicts. This expansion results in a better marginal seal, explaining its good results in microleakage tests. However, this expansion may lead to fractures of the remaining dental structure, and Coltosol ${ }^{\circledR}$ maladjustment in the occlusal sense, which may result in microleakage [20, 27-30]. Tennert et al., [22], showed that fractures can occur in four days, when Coltosol ${ }^{\circledR}$ is used in temporary sealing, in extensive Class II coronary cavities.

It is important to emphasize that, in order to be effective, it is necessary that temporary restorative materials present, besides satisfactory antimicrobial activity, other characteristics: adequate sealing of the cement-tooth interface, dimensional alteration similar to the tooth, abrasion resistance, compression and ease of insertion and removal of the cavity $[20,30]$.

The use of temporary coronary seal materials between sessions or at the end of endodontic therapy is one of the determinants of treatment success or failure $[20,30]$. These materials are intended to temporarily seal the tooth, preventing the entry of fluids, microorganisms and other debris into the root canal system and prevent the loss of medication [20, 25].

Coronal temporary seal materials should exhibit adhesiveness, low solubility, high mechanical strength, dimensional stability with a similar coefficient to dental tissue, antimicrobial activity, aesthetically acceptable thermal expansion and allow easy placement and removal in the oral cavity [22, 23]. However, the type of material, improper preparation of the cavity, misalignment and maladaptation of the material in the cavity walls, and the absence of a temporary crown seal of dental wear can lead to microleakage as well as unwanted expansion leading the formation of cracks in teeth $[22,23]$.

\section{Conclusion}

Chlorhexidine gluconate, sodium hypochlorite and Coltosol ${ }^{\circledR}$ have great fundamental properties for endodontic treatment and neither product can be disregarded. It is only necessary to analyze in detail when hypochlorite should be used and when chlorhexidine gluconate can be used that can be used alternately in the preparation of the endodontic canal and should not be used simultaneously, since the interaction between the two products provides a high toxicity. Already Coltosol ${ }^{\circledR}$ prey expansion can cause significant strains in the remaining coronary structure. Teeth that have $1.0 \mathrm{~mm}$ thick walls may be cracked after the shutter expands.

\section{References}

[1]. Palma Almeida AN, Mageste Duque TH, De Carvalho MA, Jose J. The use of chlorhexidine in endodontics. UNINGÁ Review. 2014 Oct 2;20(2).

[2]. Borin G, Becker AN, Oliveira EP. The history of sodium hypochlorite and its importance as an auxiliary substance in the mechanical chemical preparation of root canals. Journal of Endodontics Research and On-Line Teaching Year. $2007 \mathrm{Jan} ; 3(5)$.

[3]. Basrani BR, Manek S, Mathers D, Fillery E, Sodhi RN, et al. Determination of 4-chloroaniline and its derivatives formed in the interaction of sodium hypochlorite and chlorhexidine by using gas chromatography. J Endod. 2010 Feb;36(2):312-4. PubMed PMID: 20113798.
[4]. Barret MT. The Dakin-carrel antiseptic solution. Dent. Cosmos. 1917 Apr;59(4):446-8.

[5]. Bui TB, Baumgartner JC, Mitchell JC. Evaluation of the interaction between sodium hypochlorite and chlorhexidine gluconate and its effect on root dentin. J Endod. 2008 Feb;34(2):181-5. PubMed PMID: 18215677.

[6]. Bonan RF, Batista AU, Hussne RP. Comparison of the Use of Sodium Hypochlorite and Chlorhexidine as Irrigating Solution in Endodontic Treatment: Literature Review. Brazilian Journal of Health Sciences.2011 Jul 12;15(2):237-44.

[7]. Chandra SS, Miglani R, Srinivasan MR, Indira R. Antifungal efficacy of $5.25 \%$ sodium hypochlorite, $2 \%$ chlorhexidine gluconate, and 17\% EDTA with and without an antifungal agent. J Endod. 2010 Apr 1;36(4):675-8. PubMed PMID:20307743.

[8]. Coolidge ED. The diagnosis and treatment of conditions resulting from diseased dental pulps. The Journal of the National Dental Association. 1919 Apr 1;6(4):337-49.

[9]. Ferraz CC, Gomes BP, Zaia AA, Teixeira FB, Souza-Filho FJ. Comparative study of the antimicrobial efficacy of chlorhexidine gel, chlorhexidine solution and sodium hypochlorite as endodontic irrigants. Braz Dent J. 2007;18(4):294-8. PubMed PMID: 18278298.

[10]. Grossman LI. Irrigation of root canals. The Journal of the American Dental Association. 1943 Dec 1;30(23):1915-7.

[11]. Gomes-Filho JE, Aurélio KG, CostaMM, Bernabé PF. Comparison of the biocompatibility of different root canal irrigants. J Appl Oral Sci. $2008 \mathrm{Mar}-$ Apr;16(2):137-44. PubMed PMID: 19089206.

[12]. Costa MICHELOTTO AL, Martins de ANDRADE B, Alves da SILVA JÚNIOR J, Blitzkow SYDNEY G. Clorexidina for endodôntica therapy. RSBO South Brazilian Journal of Densitry. 2008;5(1).

[13]. Marion, Jefferson José de Carvalho et al. Chlorhexidine and its applications in Endodontics: A literature review. Dental Press Endod. 2013;3(3):36-54.

[14]. Pretel H, Bezzon F, Faleiros FB, Dametto FR, Vaz LG. Comparison between irrigation solutions in endodontics: chlorhexidine $\mathrm{x}$ hypochloritoe. RGO. Revista Gaúcha de Odontologia (Online). 2011 Jun;59:127-32.

[15]. Ribeiro EC, dos Santos M, Siqueira EL, Nicoletti MA. Sodium Hypochlorite in Endodontics. Brazilian Journal of Health. 2010 Jul 14;1(1).

[16]. Seixas FH. Histological evaluation of root canal cleansing promoted by different irrigation methods and tomographic analysis of the apical area at working length. (Doctoral dissertation, University of São Paulo).

[17]. Semenoff TA, Semenoff-Segundo A, Borges AH, Pedro FM, Caporossi LS, et al. Antimicrobial activity of $2 \%$ chlorhexidine gluconate, $1 \%$ sodium hypochlorite and paramonochlorophenol combined with furacin against $\mathrm{S}$. aureus, C. albicans, E. faecalise and P. aureginosa. Odonto Science Magazine. 2010;25(2):174-7.

[18]. Só MV, Vier-Pelisser FV, Darcie MS, Smaniotto DG, Montagner F, Kuga MC. Pulp tissue dissolution when the use of sodium hypochlorite and EDTA alone or associated. Odonto Science Magazine. 2011;26(2):156-60.

[19]. Walker, Alfred. A definitive and dependable theraphy for pulpless teeth. J Amer Dent Assoc. 1936Aug;23(2):1418-1425.

[20]. Milani S, Seraj B, Heidari A, Mirdamadi A, Shahrabi M. Coronal Sealing Capacity of Temporary Restorative Materials in Pediatric Dentistry: A Comparative Study. Int J Clin Pediatr Dent. 2017Apr-Jun;10(2):115-118.PubMed PMID: 28890608.

[21]. Pytko-Polończyk J, Antosik A, Zajac M, Szlósarczyk M, Krywult A, Jachowicz $R$, et al. development and verification of new solid dental filling temporary materials containing zinc. formula development stage. Acta Pol Pharm. 2016 May-Jun;73(3):749-54.PubMed PMID: 27476293.

[22]. Tennert C, Fischer GF, Vach K, Woelber JP, Hellwig E, Polydorou O. A temporary filling material during endodontic treatment may cause tooth fractures in two-surface class II cavities in vitro. Clin Oral Investig. 2016 Apr;20(3):615-20. PubMed PMID: 26243457.

[23]. Milani AS, Froughreyhani M, Mohammadi H, Tabegh FG, Pournaghiazar F. The effect of temporary restorative materials on fracture resistance of endodontically treated teeth. Gen Dent. 2016; 64(1):e1-4. PubMed PMID: 26742176.

[24]. Domingos HB, Gonçalves LS, de Uzeda M. Antimicrobial activity of a temporary sealant used in endodontic treatment: An in vitro study. Eur J Dent 2015 Jul-Sep;9(3):411-4. PubMed PMID: 26430372.

[25]. Nóbrega LM, Delboni MG, Martinho FC, Zaia AA, Ferraz CC, Gomes BP. Treponema diversity in root canals with endodontic failure. Eur J Dent 2013; 7(1):61-8. PubMed PMID: 23408792.

[26]. Al-Hezaimi K, Naghshbandi J, Oglesby S, Simon JH, Rotstein I. Human saliva penetration of root canals obturated with two types of mineral trioxide aggregate cements. J Endod. 2005 Jun;31(6):453-6. PubMed PMID: 15917686.

[27]. Laustsen MH, Munksgaard EC, Reit C, Bjorndal L. A temporary filling material may cause cusp deflection, infractions and fractures in endodonticaly treated teeth.Int Endod J. 2005 Sep;38(9):653-7. PubMed PMID: 


\section{9}

[28]. Martins LA, Gomes BPFA. In vitro evaluation of the Coltosol ${ }^{\circ}$ prey time used as temporary sealant material and the protection of gutta-percha after endodontic treatment. [Monograph] Universidade Estadural de Campinas. Faculty of Dentistry of Piracicaba. 2008.

[29]. Pereira, K. M. M. In Vitro Analysis of Coronary Sealant in Provisional Restorations and Dental Permeability after Endodontic Treatment. 2006. 82f.
Dissertation (Master in Dentistry) - Faculty of Dentistry, Federal University of Pará, Belém, 2006.

[30]. Salazar-Silva JR, Pereira RC, Ramalho LM. Importance of temporary sealing in the success of endodontic treatment. Pesqui. bras pediatric dentistry clinic integral. 2004;4(2):143-9. 